\title{
Rapid Enzymatic Test for Phenotypic HIV Protease Drug Resistance
}

\author{
Dieter Hoffmann ${ }^{1}$, Irmgard Assfalg-Machleidt ${ }^{2}$, \\ Hans Nitschko', Klaus von der Helm¹, \\ Ulrich Koszinowski ${ }^{1}$ and Werner Machleidt ${ }^{2, *}$ \\ ${ }^{1}$ Max von Pettenkofer-Institut, Abteilung für Virologie \\ der Ludwig-Maximilians-Universität, Pettenkoferstr. 9a, \\ D-80336 München, Germany \\ ${ }^{2}$ Adolf-Butenandt-Institut für Physiologische Chemie, \\ Physikalische Biochemie und Zellbiologie der \\ Ludwig-Maximilians-Universität, Schillerstr. 42, \\ D-80336 München, Germany \\ ${ }^{*}$ Corresponding author
}

A phenotypic resistance test based on recombinant expression of the active HIV protease in E. coli from patient blood samples was developed. The protease is purified in a rapid one-step procedure as active enzyme and tested for inhibition by five selected synthetic inhibitors (amprenavir, indinavir, nelfinavir, ritonavir, and saquinavir) used presently for chemotherapy of HIV-infected patients. The HPLC system used in a previous approach was replaced by a continuous fluorogenic assay suitable for high-throughput screening on microtiter plates. This reduces significantly the total assay time and allows the determination of inhibition constants $\left(K_{\mathrm{i}}\right)$. The Michaelis constant $\left(K_{\mathrm{m}}\right)$ and the inhibition constant $\left(K_{\mathrm{i}}\right)$ of recombinant wild-type protease agree well with published data for cloned HIV protease. The enzymatic test was evaluated with recombinant HIV protease derived from eight HIV-positive patients scored from 'sensitive' to 'highly resistant' according to mutations detected by genotypic analysis. The measured $K_{\mathrm{i}}$ values correlate well with the genotypic resistance scores, but allow a higher degree of differentiation. The non-infectious assay enables a more rapid yet sensitive detection of HIV protease resistance than other phenotypic assays.

Key words: Fluorogenic assay/High-throughput screening/HIV protease/HIV protease inhibitor/ Quenched substrate/Resistance.

\section{Introduction}

Introduction of HAART (Highly Active Antiretroviral Therapy) has significantly improved both life expectance and quality of HIV-positive patients (Richman, 2001). The viral reverse transcriptase (RT) and protease (PR) are the target enzymes for a combined therapy with reverse tran- scriptase inhibitors (RTI) and protease inhibitors (PI). However, lifelong therapy and a high mutation rate of the virus lead to the emergence of strains resistant to currently used drugs. Resistance to the applied antiretroviral therapy results in increasing plasma viral load and concomitant decrease of the CD4 cell count.

An increase of resistance in newly infected persons from 4\% in 1996-1998 to $17 \%$ in 1999-2001 has been observed (Ristig et al. , 2002), and complex mutation patterns have been identified in individual patients. Because of their growing importance, various resistance assays have been developed and incorporated into patient management. The common rationale of these assays is to detect resistance when rising viral loads indicate failing antiretroviral therapy.

There are two different approaches for the determination of HIV resistance: genotypic and phenotypic assays. Genotypic resistance tests are based on the detection of mutations in the RT and/or PR gene, mostly done by nucleotide sequencing, and assessment of their association with drug resistance using commercial software or databases from the Internet, or expert advice. Phenotypic assays measure empirically the sensitivity of the RT and/or PR toward the therapeutically used inhibitors (Harrigan and Cote, 2000; Schmidt et al., 2002). Thus phenotypic resistance factors are derived directly from experimental values, whereas in genotypic analysis the degree of resistance is deduced by interpretation of different mutations and their interactions based on phenotypic and clinical experience. Most phenotypic resistance assays measure the effect of PI and/or RTI on HIV replication in cell culture (Garcia-Lerma and Heneine, 2001). RT and PR genes are amplified from patient material and inserted into an HIV vector deficient for the respective genes; these constructs are then transfected into cultured cells permissive for HIV replication. Replication of the recombinant virus is determined in the presence and absence of RTI or PI using reporter genes for quantification. Two test systems are commercially available, Antivirogram (Virco, Mechelen, Belgium; Hertogs et al., 1998) and PhenoSense (ViroLogic, South San Francisco, USA; Petropoulos et al., 2000). These assays are complex, very laborious and expensive. They require several weeks for completion (Flexner, 2000). Furthermore, they cannot detect the so-called 'quasispecies' (Domingo et al., 1985, 1995) present in low proportions (Rodriguez-Rosado et al., 1999; Petropoulos et al., 2000). Distinct subpopulations may be selected for in replication-based assays, leading to erroneous resistance factors that are not representative for the patient's virus population. 
In view of the increasing spread of inhibitor-resistant HIV strains, indications for resistance testing have been expanded (EuroGuidelines Group for HIV Resistance, 2001), including primary testing even before the initiation of HAART. In these clinical situations, a sensitive detection of viral subpopulations within a short diagnostic time seems highly desirable. To approach these requirements, we have introduced an enzymatic assay for the inhibition of patient-derived recombinant HIV protease by therapeutical PI using HPLC methodology (Gehringer et al., 2003). Here we describe an improved assay comprising recombinant expression of $\mathrm{PR}$ from patient-derived RNA/cDNA in E. coli cells and measurement of the enzymatic activity with a fluorogenic substrate in a microtiter plate-based high-throughput system. This test is the first that allows a precise determination of individual inhibition constants $\left(K_{\mathrm{i}}\right)$ of therapeutic PI for patient-derived PR and thus seems suitable as a fast PR-based phenotypic resistance test in clinical virology.

\section{Results}

\section{Expression and Purification of Patient-Derived HIV Protease}

Starting with viral RNA from patient plasma, reverse-transcribed into CDNA, HIV PR for the resistance assays was obtained by expression of the PCR-amplified PR gene in E. coli as described in Materials and Methods. Taking advantage of the high acid stability of PR, the enzyme was purified in a one-step acid procedure (von der Helm et al., 1994). As reference for the establishment of the test system, recombinant HIV-1 wild-type PR (clade B MVP89987 isolate; Gürtler et al., 1994) was expressed and purified as above and then further purified in a second step resulting in $>70 \%$ purity (von der Helm et al., 1994; Gehringer et al., 2003). Preparation of recombinant PR from patient plasma takes 5 days and can be paused and continued later at several preparation levels of the protocol.

\section{PR Activity Assay}

Enzymatic activity of HIV PR was measured with the quenched fluorogenic peptide substrate DABCYL- $\gamma$ Abu-Ser-GIn-Asn-Tyr-Pro-Ile-Val-GIn-EDANS that contains the gag/p17/p24 cleavage site of the gag precursor substrate between Tyr and Pro (Matayoshi et al., 1990). This octapeptide comprising the cleavage site is C-terminally linked to the fluorophore EDANS that is quenched by the N-terminal DABCYL residue via intramolecular fluorescence resonance energy transfer (FRET). Cleavage by HIV PR leads to increased fluorescence. At $480 \mathrm{~nm}$ emission wavelength equimolar solutions of the cleavage products and of pure EDANS generated the same fluorescence signal (data not shown), allowing calibration with EDANS (see below).

The fluorogenic assay was established in cuvettes and

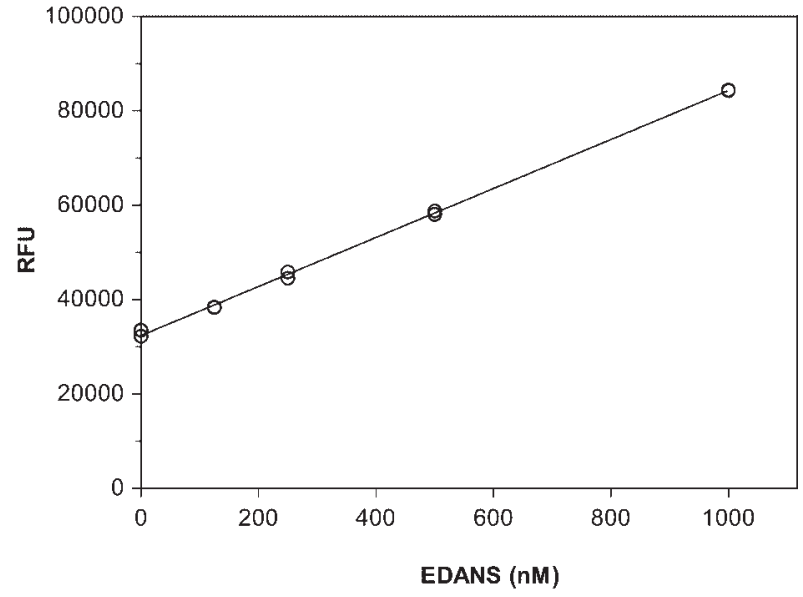

Fig. 1 EDANS Calibration of Microtiter Plate Fluorescence Readings.

RFU, relative fluorescence units. The calibration line (slope: 51.8 RFU $\times \mathrm{nM}^{-1}$ ) was obtained by linear regression analysis of the data measured in duplicate in different wells $(R=0.99988)$.

later transferred to 96-well microtiter plates (see Materials and Methods for detailed test protocols). A relatively high DMSO concentration (10\%) improved the solubility of both the hydrophobic substrate and PR without significantly affecting protease activity. Addition of the detergent NP-40 in a concentration above the critical micellar concentration stabilized the protease, ensuring a constant proteolytic activity during the duration of the test (data not shown). Thus even low residual PR activities in the range of $0.2-1 \mathrm{~nm} \times \mathrm{min}^{-1}$ could be reproducibly determined. From several types of black 96 -well plates, those with a clear bottom allowed the most sensitive detection of fluorescence through the bottom of the wells. Calculation of reaction rates $\left(n M \times \mathrm{min}^{-1}\right)$ from the progress curves was based on calibration with EDANS in the presence of substrate $(10 \mu \mathrm{M})$. Figure 1 shows a typical calibration curve fitted to 5 data points measured on microtiter plates with different EDANS concentrations that were selected according to the expected substrate turnover during the whole duration of an assay. The linear correlation between fluorescence signal and EDANS concentration indicates the absence of significant intermolecular quenching within the investigated concentration range. The slope of the calibration line (51.8 RFUx $\mathrm{nM}^{-1}$ in Figure 1) was used to convert the sampled fluorescence signals (RFU) into the concentrations of the fluorescent cleavage product (nM). The reaction rate, expressed as increase of product concentration per min (nM $\left.\times \min ^{-1}\right)$, was stable over the measurement time under conditions of negligible substrate depletion.

\section{Determination of Inhibition Constants}

The inhibition of PR by five therapeutically employed PI (amprenavir, indinavir, nelfinavir, ritonavir, and saquinavir) was determined in our test system. Dependence of the residual activities $\left(\mathrm{v}_{\mathrm{i}} / \mathrm{v}_{\mathrm{o}}\right.$ in the presence of inhibitor) on PI 


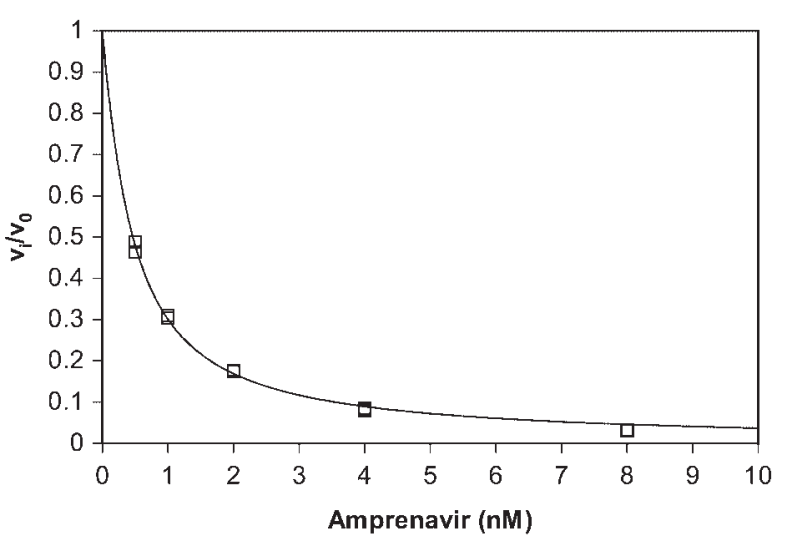

Fig. 2 Inhibition of a Patient-Derived PR by Amprenavir. $v_{o}$, initial reaction rate in the absence of inhibitor; $v_{i}$, reaction rates in the presence of increasing concentrations of amprenavir. The inhibition curve (line) was obtained by fitting the data (measured in duplicate in different wells) to equation (1).

Table 1 Amprenavir Titration of Wild-Type and Patient-Derived HIV Protease.

\begin{tabular}{llll}
\hline HIV PR & $\begin{array}{l}\text { Initial rate, } \\
\left(\mathrm{nm} \times \mathrm{vmin}^{-1}\right)\end{array}$ & $\begin{array}{l}\text { PR concentration, } \mathrm{E}_{\mathrm{t}} \\
(\mathrm{nm})\end{array}$ & $\begin{array}{l}k_{\text {cat }}[\mathrm{S}]=10 \mu \mathrm{M} \\
\left(\mathrm{s}^{-1}\right)\end{array}$ \\
\hline WT & 189 & 8.1 & 0.39 \\
Mutant a & 205 & 26.8 & 0.13 \\
PR 4 & 195 & 3.7 & 0.88 \\
PR 7 & 191 & 3.5 & 0.91 \\
PR 8 & 197 & 3.4 & 0.97 \\
PR 6a & 174 & 4.5 & 0.64 \\
PR 6b & 203 & 5.2 & 0.65 \\
\hline
\end{tabular}

The total active PR concentration, $E_{t}$, was obtained by fitting the experimental data from quasi-titration with amprenavir of WT PR, mutant a (MVP-899/R1; Eberle et al., 1995) and four patientderived PR (PR 4-8) to equation (1). PR 6 was expressed two times independently from the same patient material (PR 6a and $6 b)$. The apparent $k_{\text {cat }}([\mathrm{S}]=10 \mu \mathrm{M})$ was calculated as $k_{\mathrm{cat}}=\mathrm{v}_{\mathrm{o}} /\left[\mathrm{E}_{\mathrm{t}}\right]$.

concentration was not linear, indicating equilibrium between enzyme and inhibitor (Figure 2). Each PI concentration was tested in duplicate, revealing high well-towell reproducibility. In order to define the type of inhibition (Bieth, 1995), classical $\left(\left[E_{t}\right] / K_{i}<0.1\right)$ or tight-binding $\left(0.1<\left(\left[E_{t}\right] / K_{i}\right)<10\right)$, we determined the total enzyme concentration, $\left[\mathrm{E}_{\mathrm{t}}\right]$, by approaching titration conditions $\left(\left[\mathrm{E}_{\mathrm{t}}\right] / K_{\mathrm{i}}\right.$ $\sim 10$ ). For this purpose, the initial rate without inhibitor was adjusted to a range of 100 to $200 \mathrm{~nm} \times \mathrm{min}^{-1}$ and the rate was followed for only a few minutes in order to minimize substrate depletion. Data $\left[\left(v_{i} / v_{o}\right)\right.$ and the corresponding $\mathrm{PI}$ concentrations] from these quasi-titration experiments (Knight, 1995) with amprenavir fitted with equation (1) (see Materials and Methods) allowed the estimation of apparent $\left[\mathrm{E}_{\mathrm{t}}\right]$ and the calculation of apparent $k_{\mathrm{cat}}=\mathrm{v}_{\mathrm{o}} /\left[\mathrm{E}_{\mathrm{t}}\right]$ at $10 \mu \mathrm{M}$ substrate concentration (Table 1). Identical results were obtained for two samples of the same patient $(6 a$ and $6 \mathrm{~b}$ ) that were amplified and expressed independently. From $k_{\text {cat }}$ the active PR concentrations in the corresponding equilibrium inhibition experiments were calculated and were found to be in the same range (0.1-0.2 nM) as the inhibition constants for wild-type PR and inhibitor-sensitive PR from patients, indicating the prevalence of tight-binding conditions. Fitting of equilibrium inhibition data with equation (1) after entering $\left[E_{t}\right]$ (calculated from the corresponding amprenavir quasititration experiment) as a fixed parameter yielded reliable results for the $K_{\mathrm{i}}$ values and the calculated resistance factors (see below and Tables 2-5). Therefore this procedure was generally applied for testing wild-type and patient-derived PR, except when patient-derived PR was highly resistant to amprenavir. In these cases of very high $K_{\mathrm{i}}$ for amprenavir, quasi-titration with amprenavir was not feasible $\left(\left[E_{t}\right] / K_{i} \sim 10\right.$ could not be reached), but as then the condition $\left[E_{t}\right] / K_{i}<0.1$ was fulfilled, the data were fitted to equation (2) for 'classical' inhibition where $\left[E_{t}\right]$ is negligible (see Materials and Methods for details).

\section{Substrate Affinity and Inhibition of Wild-Type PR}

As a reference for the analysis of patient-derived PR, we determined the enzymatic parameters $\left(K_{\mathrm{m}}, k_{\mathrm{cat}}\right)$ of recombinant wild-type (WT) PR and its inhibition constants $\left(K_{\mathrm{i}}\right)$ for the five therapeutic PI. The Michaelis-Menten constant of WT PR was determined by measuring the substrate turnover at different substrate concentrations and fitting the data to the Michaelis-Menten equation (data not shown). The poor solubility of substrate prevented the use of concentrations higher than $60 \mu \mathrm{M}$. For WT PR we obtained a $K_{\mathrm{m}}$ of $80 \mu \mathrm{m}$, comparing well with $103 \mu \mathrm{m}$ reported previously (Matayoshi et al., 1990). This value confirms that the substrate concentration of $10 \mu \mathrm{m}$ used in our assays is well below $K_{m}$ and correction of $K_{\mathrm{i}}$ for substrate competition according equation (3) is not relevant.

WT PR either highly purified ( $>70 \%$ ) or one-step purified (von der Helm et al., 1994) was tested for inhibition by Pls in cuvettes and on microtiter plates. To achieve high accuracy, the $K_{\mathrm{i}}$ for WT PR was determined from 15 to 20 data points. Table 2 shows that inhibition constants are not significantly dependent on the degree of enrichment of HIV PR or on the format (cuvette or microtiter plate) of the enzymatic test. According to these data, the presence of contaminating E. coli proteins (data not shown) does not influence the inhibition constants. Our results agree well with data from the literature where the extent of cleaved substrate was determined by ion-exchange HPLC (Klabe et al., 1998) or with the same fluorogenic peptide substrate as in this work (Markgren et al., 2001). The crude preparation of patient-derived PR used in our work was therefore sufficient to obtain accurate and valid results, a feature that facilitates and accelerates the test procedure considerably.

\section{PI Resistance of Patient-Derived HIV Proteases}

To evaluate the potential of our test system for resistance screening, we investigated the inhibition of recombinantly expressed HIV PR from 8 patients that had been geno- 
Table 2 Inhibition Constants $\left(K_{j}\right)$ for WT PR of Five Therapeutic PI.

\begin{tabular}{llllll}
\hline & $\begin{array}{l}\text { WT PR } \\
\text { (purified }>70 \%), \\
\text { cuvette }\end{array}$ & $\begin{array}{l}\text { WT PR one-step } \\
\text { purification, } \\
\text { cuvette }\end{array}$ & $\begin{array}{l}\text { WT PR one-step } \\
\text { purification, } \\
\text { microtiter plate }\end{array}$ & $\begin{array}{l}\text { WT PR } \\
\text { (Klabe et al., } \\
\left.1998^{\mathrm{a}}\right)\end{array}$ & $\begin{array}{l}\text { WT PR } \\
\text { (Markgren } \\
\text { et al., 2000 })\end{array}$ \\
\hline PI & $K_{\mathrm{i}}^{\mathrm{C}}(\mathrm{nm})$ & $K_{\mathrm{i}}^{\mathrm{C}}(\mathrm{nM})$ & $K_{\mathrm{i}}^{\mathrm{M}}(\mathrm{nM})$ & $K_{\mathrm{i}}(\mathrm{nm})$ & $K_{\mathrm{i}}(\mathrm{nm})$ \\
\hline APV & $0.21 \pm 0.049$ & $0.19 \pm 0.10$ & $0.24 \pm 0.13$ & n.d. & n.d. \\
IDV & $0.16 \pm 0.028$ & $0.29 \pm 0.075$ & $0.15 \pm 0.056$ & 0.14 & 0.31 \\
NFV & $0.38 \pm 0.032$ & $0.37 \pm 0.046$ & $0.36 \pm 0.146$ & 0.28 & 0.54 \\
RTV & $0.16 \pm 0.035$ & $0.16 \pm 0.023$ & $0.16 \pm 0.035$ & 0.17 & 0.59 \\
SQV & $0.066 \pm 0.011$ & $0.11 \pm 0.089$ & $0.085 \pm 0.045$ & 0.15 & 0.23 \\
\hline
\end{tabular}

$K_{\mathrm{i}}$ obtained in the cuvette $\left(K_{\mathrm{i}} \mathrm{C}\right)$ and in the microtiter plate $\left(K_{\mathrm{i}}^{\mathrm{M}}\right)$ assay \pm standard deviation. Abbreviations for PI: APV, amprenavir; IDV, indinavir; NFV, nelfinavir; RTV, ritonavir; SQV, saquinavir; n.d., not determined.

${ }^{a}$ Determined by HPLC analysis of the cleavage products of a peptide substrate.

bDetermined with the same fluorogenic peptide as in this study.

Table 3 Enzymatic and Genotypic Resistance Factors of Four Highly Resistant Patients.

\begin{tabular}{|c|c|c|c|c|c|c|c|c|}
\hline \multirow[b]{2}{*}{$\mathrm{PI}$} & \multicolumn{2}{|c|}{$\begin{array}{l}\text { Patient } 38 \\
(12 \text { amino acid } \\
\left.\text { exchanges }^{a}\right)\end{array}$} & \multicolumn{2}{|c|}{$\begin{array}{l}\text { Patient } 66 \\
\text { (15 amino acid } \\
\left.\text { exchanges }^{b}\right)\end{array}$} & \multicolumn{2}{|c|}{$\begin{array}{l}\text { Patient } 202 \\
(12 \text { amino acid } \\
\left.\text { exchanges }^{c}\right)\end{array}$} & \multicolumn{2}{|c|}{$\begin{array}{l}\text { Patient } 205 \\
(12 \text { amino acid } \\
\left.\text { exchanges }^{d}\right)\end{array}$} \\
\hline & $\mathrm{R}_{\mathrm{enz}}{ }^{\mathrm{C}}$ & $\mathrm{R}_{\mathrm{gen}}$ & $\mathrm{R}_{\mathrm{enz}}{ }^{\mathrm{C}}$ & $\mathrm{R}_{\mathrm{gen}}$ & $\mathrm{R}_{\mathrm{enz}}{ }^{\mathrm{M}}$ & $\mathrm{R}_{\mathrm{gen}}$ & $\mathrm{R}_{\mathrm{enz}}{ }^{\mathrm{M}}$ & $\mathrm{R}_{\text {gen }}$ \\
\hline APV & 1.6 & 2 & 3.1 & 2 & 11 & 4 & 433 & 6 \\
\hline IDV & 12 & $>10$ & 15 & 10 & 39 & $>10$ & 343 & $>10$ \\
\hline NFV & 21 & $>10$ & 37 & 10 & 40 & $>10$ & 397 & $>10$ \\
\hline RTV & 17 & 8 & 48 & 10 & 45 & $>10$ & 295 & $>10$ \\
\hline SQV & 298 & $>10$ & 58 & 10 & 175 & $>10$ & 2658 & $>10$ \\
\hline
\end{tabular}

The enzymatic resistance factors $\left(\mathrm{R}_{\text {enz }}\right)$ were calculated from the $K_{\mathrm{i}}$ values determined in cuvette format $\left(R_{e n z}{ }^{C}\right)$ and microtiter plate format $\left(R_{e n z}{ }^{M}\right)$. Resistance factors predicted from genotypic analysis $\left(R_{\text {gen }}\right.$, see Materials and Methods) are shown for comparison. For PI abbreviations see Table 2.

aL10I, S37N, I54L, D60E, L63P, I64V, A71V, G37S, V77I, I84V, L90M, 193L.

bK20R, E35D, M36I, S37N, M46L, R57K, I62V, L63P, A71V, I72R, G73S, V77I,

V82I, L90M, 193L.

'L10I, V11I, E35D, S37N, M46I, L63P, H69R, A71V, G73T, I84V, L90M, I93L.

dL10I, I15V, K20V, S37N, M46I, I62V, L63P, A71T, G73S, I84V, I85V, L90M.

typically classified and scored by nucleotide sequencing (Gehringer et al., 2003). The respective resistance of patient-derived PR to PI in our assay was expressed by enzymatic resistance factors $\left(\mathrm{R}_{\text {enz }}\right)$ reflecting the ratio $K_{\mathrm{i}}$ (patient) $/ K_{\mathrm{i}}(\mathrm{WT})$. These enzymatically determined resistance factors were compared with genotypic resistance factors $\left(R_{\text {gen }}\right)$ derived from the number and nature of mutations present in the predominant subpopulation (Tables 3 and 4). Table 3 shows that highly resistant PR (as expected from their genotype) can be detected by their up to 2600 fold reduced affinity (i.e. increased $K_{\mathrm{i}}$ ) for the respective PI. Obviously, the $K_{\mathrm{i}}$ even of heavily mutated proteases $\left(R_{\text {gen }}>10\right)$ could be determined in our assay. The affinitybased resistance factors obtained with our assay show a good overall correlation to the corresponding genotypic resistance factors, but allow a much higher degree of differentiation than the genotypic scores that are limited to a range between 1 and 10 .
The results shown in Table 4 suggest that PR classified as 'sensitive' or 'low resistant' by the genotypic score can be more precisely discriminated from WT PR in our enzymatic assay, thus improving the sensitivity of detecting resistant populations.

\section{Defined Mixtures of Highly Resistant PR and WT PR}

It has been previously shown by the HPLC-based activity assay that in mixtures of resistant PR and WT PR the ratio between different 'quasispecies' remained unchanged by simultaneous expression of their genes in $E$. coli (Gehringer et al., 2003). We determined the resistance factors with our fluorogenic assay after mixing WT PR with different proportions of highly resistant patientderived PR. The enzymatic test was able to detect a fraction as low as $5 \%$ saquinavir-resistant PR 205 within sensitive WT PR (Table 5). 
Table 4 Resistance Profiles of Four Sensitive to Intermediate Resistant Patients.

\begin{tabular}{|c|c|c|c|c|c|c|c|c|}
\hline \multirow[b]{2}{*}{ PI } & \multicolumn{2}{|c|}{$\begin{array}{l}\text { Patient } 64 \\
(8 \text { amino acid } \\
\text { exchanges }^{\mathrm{a}} \text { ) }\end{array}$} & \multicolumn{2}{|c|}{$\begin{array}{l}\text { Patient } 68 \\
\text { (7 amino acid } \\
\left.\text { exchanges }^{b}\right)\end{array}$} & \multicolumn{2}{|c|}{$\begin{array}{l}\text { Patient } 71 \\
(9 \text { amino acid } \\
\left.\text { exchanges }^{c}\right)\end{array}$} & \multicolumn{2}{|c|}{$\begin{array}{l}\text { Patient } 4 \\
\text { (4 amino acid } \\
\text { exchanges }^{d} \text { ) }\end{array}$} \\
\hline & $\mathrm{R}_{\mathrm{enz}}^{\mathrm{M}}$ & $\mathrm{R}_{\mathrm{gen}}$ & $\mathrm{R}_{\mathrm{enz}}^{\mathrm{M}}$ & $\mathrm{R}_{\text {gen }}$ & $\mathrm{R}_{\mathrm{enz}}{ }^{\mathrm{M}}$ & $\mathrm{R}_{\mathrm{gen}}$ & $\mathrm{R}_{\mathrm{enz}}{ }^{\mathrm{C}}$ & $\mathrm{R}_{\mathrm{gen}}$ \\
\hline APV & 1.4 & 1 & 0.46 & 1 & 0.46 & 1 & 4.2 & 2 \\
\hline IDV & 2.1 & 1 & 0.87 & 1 & 3.3 & 1 & 3.4 & 2 \\
\hline NFV & 3.3 & 1 & 3.0 & 1 & 5.8 & 3 & 5.0 & 3 \\
\hline RTV & 2.1 & 1 & 1.4 & 1 & 3.9 & 1 & 4.0 & 2 \\
\hline SQV & 3.6 & 1 & 1.3 & 1 & 6.6 & 3 & 8.2 & 3 \\
\hline
\end{tabular}

For abbreviations see Tables 2 and 3.

aE35D, M36I, S37N, I62V, L63P, V77I, V82I, I93L.

bE35D, M36I, S37N, I62V, L63P, C67E, H69K.

'E35D, M36I, S37N, I62V, L63P, C67E, H69K, A71T, L90M.

dM36I/M, L63P, V77I, L90M.

Table 5 Enzymatic Resistance Factors Determined after Mixing WT PR with Different Amounts of Highly Resistant PR.

\begin{tabular}{lcrlr}
\hline $\begin{array}{l}\text { Portion } \\
\text { of patient PR }\end{array}$ & $\begin{array}{l}10 \% \\
\text { \#202 }\end{array}$ & $\begin{array}{l}15 \% \\
\text { \#202 }\end{array}$ & $\begin{array}{l}\text { \#\% } \\
\text { \#205 }\end{array}$ & $\begin{array}{r}50 \% \\
\text { \#205 }\end{array}$ \\
\hline APV & 1.7 & 2.1 & 2.4 & 6.7 \\
IDV & 3.1 & 5.7 & 2.7 & 14.7 \\
NFV & 1.5 & 3.8 & 2.3 & 16.9 \\
RTV & 2.4 & 6.5 & 4.8 & 20.8 \\
SQV & 4.8 & 17.6 & 7.8 & 95.2 \\
\hline
\end{tabular}

Highly resistant PR was obtained from patient \#202 and patient \#205, respectively (see Table 3 for the corresponding resistance profiles). For PI abbreviations see Table 2.

\section{Discussion}

A phenotypic assay for testing resistance of HIV protease to therapeutically used protease inhibitors has been developed, based on direct measurement of inhibition of patient-derived enzymatically active PR using a low molecular weight synthetic substrate. In contrast to previous approaches to determine the susceptibility of PR to inhibitors, this assay provides direct enzymatic data on the affinity of the PI used in therapy for the HIV protease population of an individual patient, which are independent of the total amount of active protease(s) present in the test. An enzymatic assay of PR activity relying on analysis of Gag-Pol cleavage products by ELISA after in vitro translation of the protease (Iga et al., 2002), has not yet been applied to fresh patient-derived material.

The gene coding for patient-derived PR is obtained from retroviral RNA extracted from blood plasma by transcription to cDNA and amplification by a nested PCR using two different pairs of primers, and is finally expressed in E. coli. A one-step acid purification procedure based on the stability of PR at low pH (von der Helm et al., 1994) leads to sufficient amounts of active protease for inhibition assays. As indicated by comparison with higher pu- rified material (Table 2), residual E. coli proteins contained in the one-step purified material do not interfere with the determination of inhibition constants. Moreover, the inhibition constants obtained with single-step purified WT PR are very close to previously reported values for homogeneous WT PR (Klabe et al., 1998, Markgren et al., 2001).

In a first approach, patient-derived PR has been expressed in $E$. coli using a similar procedure, starting from patient DNA and measuring the recombinant HIV protease activity by HPLC analysis of the cleavage products of a peptide substrate (Gehringer et al., 2003). It was shown that the concentration of the respective PI resulting in a $50 \%$ enzyme inhibition $\left(\mathrm{IC}_{50}\right)$ correlates well with clinical parameters and blind genotypic analysis. Moreover, genotypic analysis revealed that the proportion of different subpopulations is not significantly altered by the amplification and cloning procedure, in contrast to cellculture based tests, where distinct subpopulations can be selected depending on their replication capacities (Kusumi et al., 1992). Extending the previous assay (Gehringer et al., 2003), we have substituted HPLC methodology by a continuous enzymatic assay with a fluorogenic peptide substrate, leading to essential improvements of two aspects: (i) true inhibition constants $\left(K_{\mathrm{i}}\right)$ of the tight-binding PI are determined, reflecting their thermodynamic affinity for the mutated PR over a wide range, independent of the actual protease concentration and experimental conditions; (ii) the microtiter plate format of the assay allows high-throughput screening of a high number of patient-derived samples within much shorter time.

Although our novel assay has been evaluated on a limited number of patients up to now, it seems to be well suited as a PR-based phenotypic resistance test in clinical virology. The resistance factors calculated from the measured $K_{\mathrm{i}}$ values correlate well with resistance factors predicted from genotypic analysis (Tables 3 and 4). However, the range between 'sensitive' and 'highly resistant' proteases is expanded, allowing more precise differenti- 
ation. The clinical significance of different inhibition constants within this range remains to be established in future studies with an extended number of patients.

The $K_{\mathrm{i}}$ values for the inhibition of patient-derived recombinant HIV PR (e.g. $0.00016 \mu \mathrm{M}$ for indinavir) are several orders of magnitudes lower than the inhibitor concentrations that have been measured in blood plasma of treated patients (e.g. $4.6 \mu \mathrm{M}$ for indinavir; Langmann et al., 2001) so that even highly resistant PR species would be expected to be completely inhibited by the plasma concentrations achieved in therapy. However, it is known that, for reasons not completely understood, much higher inhibitor concentrations than the thermodynamic $K_{\mathrm{i}}$ values of isolated PR are required for significant inhibition of intracellular virus replication. Extracellular $I C_{50}$ in the micromolar range have been reported for the inhibition of virus replication in infected lymphocytes and monocytes/macrophages (Perno et al., 1998). The PI plasma levels achieved in therapy (Langmann et al., 2001) are close to or frequently below the levels required for $95 \%$ suppression of WT virus in vivo (e.g. $0.2 \mu \mathrm{M}$ indinavir; Durant et al., 2000). In this situation, even a moderate increase of $K_{\mathrm{i}}$ due to mutated PR could be responsible for therapeutic failure.

Concerning the evaluation of low or intermediate resistant proteases, the fluorescence assay seems to be significantly more sensitive than genotypic analysis (Table 4). Even if proteases with a moderate increase of inhibition constants would cause no clinically significant resistance, these proteases are more likely to develop a relevant mutation pattern (Gehringer et al., 2000). Moreover, low phenotypic resistance factors can also be caused by highly resistant 'quasispecies' (Domingo et al., $1985,1995)$ present in a low percentage of the whole HIV population. To simulate this condition in the enzymatic test, we measured defined mixtures of highly resistant PR and WT PR (Table 5). A portion of 5-10\% highly resistant $\mathrm{PR}$ was detected in these experiments. The resistance factors for highly resistant patients can be more precisely differentiated by our enzymatic assay than by genotypic analysis (Table 3). Exact quantitative discrimination between high resistance factors might be helpful in heavily pre-treated patients to find inhibitors that are to some extent still effective in antiviral therapy (Miller, 2001).

As compared to cell culture-based phenotypic resistance tests, the main advantages of our enzymatic assay are the rapid and relatively inexpensive test procedure in connection with its high sensitivity. Results of the enzymatic PR assay are available after one week (5 days for amplification, cloning, expression and PR isolation; $5 \mathrm{~h}$ /patient for the microtiter plate inhibition test), while cell culture-based tests usually require two to several weeks. This may be important for example in acute HIV infections or in infections during pregnancy, both indications for rapid resistance testing (EuroGuidelines Group for HIV Resistance, 2001). The estimated price for resistance determination with our assay is less than half the cost of the commercially available phenotypic tests
(Flexner, 2000; Hanna and Caliendo, 2001). The sensitivity of our assay is an important advantage over cell culture-based tests, since the lower sensitivity of the cell culture-based phenotypic assays is considered an inherent drawback compared to genotypic tests (RodriguezRosado et al., 1999). For instance, these procedures can reveal even highly resistant 'quasispecies' only when they represent more than $10-40 \%$ of all relevant molecules (Petropoulos et al., 2000).

High sensitivity would be particularly desirable when resistant 'quasispecies' are likely to be present in a low proportion, as in primary infection before therapy is initiated or when planning an intended therapy change for other reasons than therapy failure, e.g. because of serious side effects. Resistant 'quasispecies' can quickly constitute the majority of the HIV population after insufficient treatment has been initiated (Hanna and Caliendo, 2001). This may be avoided when resistant strains are detected at an early stage and therapy is modified according to the test results.

Of great practical importance is the fact that in our entire assay procedure no potentially infectious HIV cell culture is utilized so that no special biosafety facility is required. An inherent limitation of our test is that it only measures HIV PR resistance and has to be complemented by a suitable enzymatic assay for resistance of RT to its inhibitors (Garcia-Lerma et al., 1999; Vasquez-Rosales et al., 1999).

In addition to resistance testing, the presented enzymatic assay may also be used in basic research as a tool to characterize new PR mutants by their enzymatic parameters $\left(K_{\mathrm{m}}, k_{\mathrm{cat}}\right)$ and by their inhibition profile with therapeutic PI. Furthermore, it may provide information on the 'fitness' of the respective HIV strain. This could be interesting in view of 'fitness' assays that are expected to be introduced as important diagnostic tools in the future (Miller, 2001).

Since the prevalence of resistance and, as a consequence, the spread of primary resistance is increasing (Ristig et al., 2002) there is a growing interest to improve the knowledge about the presence of resistant strains in different populations (Miller, 2001). An enzymatic test like the one presented here would be advantageous for testing a large number of patient isolates with as little expenses as possible. Cross-resistance is an important problem particularly in therapy with PI, leading to resistance toward antiretroviral drugs before their approval. Thus several authors (Palmer et al., 1999; Harrigan and Cote, 2000) recommend testing newly developed inhibitors against highly resistant clinical isolates. For this purpose our test might be useful, because it is easily standardized and suited for high-throughput screening.

In conclusion, the enzymatic assay for HIV PR resistance described here seems to be a promising novel alternative to many established PR resistance assays and should therefore be further evaluated in clinical studies with a greater number of patients. 


\section{Materials and Methods}

\section{Recombinant Expression of HIV PR}

The tested patient material was mainly obtained from J. Eberle, Clinical Virology, Max von Pettenkofer Institute, Munich. RNA was extracted from EDTA plasma using the 'High Pure Viral Nucleic Acid Kit' (Roche, Mannheim, Germany) and reverse transcribed into cDNA containing both the PR- and RT-gene. The genes for these two enzymes were amplified in a first PCR round using the primers geno1 and geno2 (designed by J. Eberle) and the 'Expand long template PCR system' (Roche).

Geno1: 5'-GGC TGT TGG AAA TGT GGA ARR GA-3'

Geno2: 5'-GCY TGC CAA TAI TCY RTC CAC C-3'.

Cycle conditions: 2.5 units enzyme mix, $1.75 \mathrm{mM} \mathrm{MgCl}_{2}, 0.35 \mathrm{~mm}$ dNTP, annealing temperature $50^{\circ} \mathrm{C}, 35$ cycles. The extraction of RNA and the first PCR round were carried out together with the genotypic resistance test in the section of clinical virology of the Max von Pettenkofer Institute (see below). The second PCR round was specific for the amplification of the PR-gene, using the primers

P3: 5'-CGG GGS TCC TTC AGA GCA GAC CAG AG-3' and P4: 5'-GCC AAG CTT TCA AAA ATT TAA AGT GCA ACC AAT-3'. Cycle conditions: 1.5 units AmpliTaq Gold, $3 \mathrm{~mm} \mathrm{MgCl}, 0.20 \mathrm{~mm}$ dNTP, annealing temperature $48^{\circ} \mathrm{C}, 40$ cycles. The PCR-reactions were carried out in an UNO II thermocycler (Biometra, Göttingen, Germany). The resulting amplicon was digested with $\mathrm{BamHI}$ and HindIII (Roche) and ligated into the vector $\mathrm{pBD}_{2}$ (Bröker, 1986) digested with the same enzymes. The ligation product was purified with QIAEX II Agarose Gel Extraction Kit (Qiagen, Hilden, Germany) and transformed into TG1 electroporation-competent E. coli cells (Stratagene, Heidelberg, Germany). The overnight culture was expanded in 500 ml LB-medium until an optical density of 0.4 to 0.6 was achieved. The cells were disrupted by ultrasonification and the HIV PR was purified by a one-step method (von der Helm et al., 1994) taking advantage of its stability at low pH. Expression of the HIV PR in E. coli cells and preparation of enzymatically active HIV proteases from patient material are described in more detail elsewhere (Gehringer et al., 2003). Subsequently, PR was precipitated with ammonium sulfate and centrifuged. The pellet was dissolved in $200-500 \mu$ l assay buffer containing $10 \%$ DMSO and centrifuged again. The PR solution could be used directly in the fluorescence test or stored at $-20^{\circ} \mathrm{C}$.

WT PR was highly purified exemplarily to check if contaminating $E$. coli proteins influence the enzymatic measurement. For this purpose, we took advantage of its hydrophobicity: the pellet from the ammonium sulfate precipitation was dissolved in a smaller amount of assay buffer $(100-200 \mu l)$ followed by centrifugation. The supernatant contained most of the more hydrophilic E. coli proteins and was discarded. Dissolving the pellet again in 200-500 $\mu$ l of assay buffer with $10 \%$ DMSO led to an highly purified, but diluted PR solution that was concentrated with a Centriprep-10 Concentrator (Amicon, Beverly, USA) following the instructor's recommendations. The purity was checked by Western Blot analysis.

\section{Measurement of PR Activity}

WT or patient-derived active protease was tested with the quenched fluorogenic peptide substrate DABCYL- $\gamma$-Abu-SerGln-Asn-Tyr-Pro-Ile-Val-Gln-EDANS (10 $\mu \mathrm{m})$ (Bachem, Heidelberg, Germany). Cleavage by the HIV PR leads to an increase in fluorescence from the unquenched fluorophore EDANS. Different concentrations of EDANS in assay buffer containing the substrate were used for calibration (see Results and Figure 1). Based on this calibration, the fluorescence data sampled at reg- ular time intervals were converted into concentrations (nM) and the reaction rates $\left(n \mathrm{n} \times \mathrm{min}^{-1}\right)$ were obtained from the slope of the product concentration progress curves.

The test was performed in assay buffer $\mathrm{pH} 4.7$, containing $50 \mathrm{~mm}$ sodium acetate, $1 \mathrm{~mm}$ EDTA, $2.5 \mathrm{~mm}$ DTT, $1.0 \mathrm{M} \mathrm{NaCl}$, $2.5 \% \mathrm{v} / \mathrm{v}$ glycerol, $10 \% \mathrm{v} / \mathrm{v}$ DMSO, $0.1 \% \mathrm{NP}-40$ (similar to the buffer used by Kraft and Wang, 1994) and $10 \mu \mathrm{M}$ of substrate. In cuvette format, the fluorescence was measured in semi-micro cuvettes (PMMA, $4 \times 10 \mathrm{~mm}$, Mueller Ratiolab, Dreieich-Buchschlag, Germany) containing a volume of $500 \mu$ with a spectrofluorometer SFM 25 (BioTek-Kontron, Neufahrn, Germany), equipped with an automated 4-sample changer (excitation: $355 \mathrm{~nm}$; emission: $490 \mathrm{~nm}$ ). In microtiter plate format, an assay volume of $200 \mu \mathrm{l}$ was used on 96-well plates ('non-binding surface' microplates; Corning, Wiesbaden, Germany) measured with a FL600 microplate reader (BioTek-Kontron) employing an excitation filter of $340 \mathrm{~nm}$ (bandwidth $40 \mathrm{~nm}$ ) and an emission filter of $485 \mathrm{~nm}$ (bandwidth $20 \mathrm{~nm}$ ).

\section{PR Inhibition by Therapeutical PI}

PR inhibition experiments were performed with the following five therapeutically used PI: amprenavir (APV), Glaxo Wellcome, Greenford, UK; indinavir (IDV), Merck Research Laboratories, Rahway, USA; nelfinavir (NFV), Agouron Pharmaceuticals Inc., La Jolla, USA; ritonavir (RTV), Abbott Laboratories, North Chicago, USA; saquinavir (SQV), Roche Products LTD., Welvyn Garden City, UK.

In cuvettes, the initial rate of WT or patient derived PR was adjusted to $10-20 \mathrm{~nm} \times \mathrm{min}^{-1}$ by addition of the proper amount of enzyme solution and was observed for up to $15 \mathrm{~min}$, before different concentrations of $\mathrm{PI}(0.25-2000 \mathrm{~nm})$ were added. Typically, a new equilibrium was reached in $\sim 1 \mathrm{~min}$, the reaction was followed for 20-30 min afterward.

On microtiter plates, the test was started with protease in each well after premixing of different concentrations of $\mathrm{PI}$, buffer and substrate. The initial rates (10-20 nM $\left.\times \mathrm{min}^{-1}\right)$ were obtained from control wells without PI. Scanning of the plate (about 2 min per cycle) was continued over a total period of 40-50 min. On a first plate, the activity of the patient-derived PR preparations $\left(\mathrm{nm} \times \mathrm{min}^{-1} \times \mathrm{ml}^{-1}\right)$ was determined for several patients in parallel. A second plate was used for titration of patient-derived PR with amprenavir to obtain precise $\left[\mathrm{E}_{\mathrm{t}}\right]$ for evaluation (see below and Results). On this plate, amounts of patient-derived PR yielding an activity of $100-200 \mathrm{~nm} \times \mathrm{min}^{-1}$ were added to different concentrations of amprenavir (see Results for details). One or two consecutive plates were required for a single patient's complete resistance profile to five currently in HIVtherapy used PI. On the first plate, five 'standard' concentrations of each of the five PI (typically 1, 2, 4, 8, and 32 nM) were measured in duplicate. For precise $K_{\mathrm{i}}$ determination of sensitive or highly resistant $\mathrm{PR}$, a second plate with lower or higher PI concentrations (in the range of $0.25 \mathrm{~nm}$ to $2 \mu \mathrm{M}$ ) was tested subsequently, if necessary.

\section{Evaluation of Inhibition Data}

For each PI concentration the steady-state rate in the presence of inhibitor, $\mathrm{v}_{\mathrm{i}}$, was divided by the initial rate in the absence of inhibitor, $v_{0}$. The resulting ratios $v_{i} / v_{0}$ and the corresponding PI concentrations were used to determine the inhibition constant $\left(K_{i}\right)$ of the investigated PI and PR by non-linear regression analysis using the commercial software FigP from Biosoft (Cambridge, UK).

$K_{\mathrm{i}}$ and the total concentration of active enzyme, $\left[\mathrm{E}_{\mathrm{t}}\right]$, were obtained by fitting the data to the general equation for competitive tight binding inhibitors (Morrison, 1969; Bieth, 1995): 
$\mathrm{v}_{\mathrm{i}} / \mathrm{v}_{\mathrm{o}}=1-\left\{\left[\mathrm{E}_{\mathrm{t}}\right]+\left[\mathrm{l}_{\mathrm{t}}\right]+K_{\text {iapp }}-\left\{\left(\left[\mathrm{E}_{\mathrm{t}}\right]+\left[\mathrm{I}_{\mathrm{t}}\right]+K_{\text {iapp }}\right)^{2}-4\left[\mathrm{E}_{\mathrm{t}}\left[\mathrm{l}_{\mathrm{t}}\right]\right\}^{1 / 2}\right\} / 2\left[\mathrm{E}_{\mathrm{t}}\right]\right.$

where

$\mathrm{v}_{\mathrm{i}}=$ steady-state rate in the presence of the inhibitor, measured as $\Delta$ [product] $\mathrm{min}^{-1}$;

$\mathrm{v}_{\mathrm{o}}=$ initial rate in the absence of the inhibitor;

$\left[E_{t}\right]=$ total concentration of the enzyme (free and bound);

$\left[\mathrm{l}_{\mathrm{t}}\right]=$ total concentration of the inhibitor (free and bound);

$K_{\text {iapp }}=$ apparent dissociation constant of the enzyme-inhibitor complex at a given substrate concentration.

When both $\left[\mathrm{E}_{\mathrm{t}}\right]$ and $K_{\text {iapp }}$ are treated as variable parameters, reliable estimates for $\left[E_{t}\right]$ but not for $K_{\text {iapp }}$ are approached under quasi-titration conditions, $\left[\mathrm{E}_{\mathrm{t}}\right] / K_{\text {iapp }}>10$; otherwise, for $\left[\mathrm{E}_{\mathrm{t}}\right]<<K_{\text {iapp }}$ (practically for $\left[E_{t}\right] / K_{\text {iapp }}<0.1$ ), equation (1) simplifies to the equation for 'classical' inhibition in which $\left[\mathrm{E}_{\mathrm{t}}\right]$ is neglected

$\mathrm{V}_{\mathrm{i}} / \mathrm{v}_{\mathrm{o}}=1 /\left(1+\left[\mathrm{I}_{\mathrm{t}}\right] / K_{\text {iapp }}\right)$

For competitive inhibition, the real $K_{\mathrm{i}}$ can be calculated from $K_{\text {iapp }}$ using the equation

$K_{\mathrm{i}}=K_{\text {iapp }} /\left(1+[\mathrm{S}] / K_{\mathrm{m}}\right)$

where

[S]=substrate concentration and $K_{\mathrm{m}}=$ Michaelis-Menten constant.

Under our experimental conditions $[\mathrm{S}]<K_{\mathrm{m}}, K_{\text {iapp }}$ and $K_{\mathrm{i}}$ are similar, because competition of the inhibitor with the substrate is negligible. $K_{\text {iapp }}$ corresponds to the $\mathrm{IC}_{50}$, the inhibitor concentration resulting in $50 \%$ inhibition of the enzymatic activity under defined experimental conditions.

To obtain resistance factors comparable to results of other phenotypic tests, the $K_{\mathrm{i}}$ of patient HIV proteases were divided by $K_{\mathrm{i}}$ of WT protease.

\section{Genotypic Resistance Analysis}

The amplified PR gene (see top of Materials and Methods) was sequenced with an ABI Prism 377 DNA sequencer (Applied Biosystems, Weiterstadt, Germany) employing the Big Dye Mix No. 4303150 (Perkin Elmer Life Sciences, Rogau-Juegesheim, Germany). Genotypic resistance factors were obtained with an in-house scoring algorithm using data from Beta-test available at the Stanford HIV RT and Protease Sequence Database (http://hivdb.stanford.edu/).

\section{Acknowledgments}

We are grateful to Frank-Detlev Goebel, Medizinische Poliklinik, Ludwig-Maximilians-Universität München, for providing plasma of HIV-infected patients and Josef Eberle, Max von PettenkoferInstitut, Ludwig-Maximilians-Universität München, for HIV-containing specimens and for performing genotypic analysis.

\section{References}

Bieth, J.G. (1995). Theoretical and practical aspects of proteinase inhibition kinetics. Methods Enzymol. 248, 59-84.

Bröker, M. (1986). Vectors for regulated high-level expression of proteins fused to truncated forms of Escherichia coli B-galactosidase. Gene Anal. Techn. 3, 53-57.

Domingo, E., Martinez-Salas, E., Sobrino F., de la Torre, J.C., Portela, A., Ortin, J., Lopez-Galindez, C., Perez-Brena, P., Villanueva, N., and Najera, R. (1985). The quasispecies (ex- tremely heterogeneous) nature of viral RNA genome populations: biological relevance-a review. Gene 40, 1-8.

Domingo, E., Holland, J.J., Bierbricher, C. and Eigen, M. (1995). Quasispecies: the concept and the word. In: Molecular Basis of Virus Evolution, A. Gibbs, C. Calisher, and F. Garcia-Arenal, eds. (Cambridge, UK: Cambridge University Press), pp. 171 180.

Durant, J., Clevenbergh, P., Garraffo, R., Halfon, P., Icard, S., Del Guidice, P., Montagene, N., Schapiro, J.M., and Dellamonica, P. (2000). Importance of protease inhibitor plasma levels in patients treated with genotypic-guided therapy: pharmacological data from the VIRADAPT study. AIDS 14, 1333-1339.

Eberle J., Bechowsky, B., Rose, D., Hauser, U., von der Helm, K., Gürtler, L., and Nitschko, H. (1995). Resistance of HIV type 1 to proteinase inhibitor Ro 31-8959. AIDS Res. Hum. Retrovir. $11,671-676$.

Ermolieff, J., Lin, X., and Tang, J. (1998). The effect of substrates on the kinetics and the in vivo threshold activity of mutant HIV1 proteases. Adv. Exp. Med. Biol. 436, 47-51.

EuroGuidelines Group for HIV Resistance (2001). Clinical and laboratory guidelines for the use for HIV-1 drug resistance testing as part of treatment management: recommendations for the European setting. AIDS 15, 309-320.

Flexner, C.F. (2000). HIV genotype and phenotype-arresting resistance? JAMA 283, 2442-2444.

Garcia-Lerma, J.G., and Heneine, W. (2001). Resistance of human immunodeficiency virus type 1 to reverse transcriptase and protease inhibitors: genotypic and phenotypic testing. J. Clin. Virol. 21, 197-202.

Garcia-Lerma, J., Schinazi, R., Juodawlkis, A., Soriano, V., Lin, Y., Tatti, K., Rimland, D., Folks, T., and Heneine, W. (1999). A rapid non-culture-based assay for clinical monitoring of phenotypic resistance of human immunodeficiency virus type 1 to lamivudine (3 TC). Antimicrob. Agents Chemother. 43, 264-270.

Gehringer, H., Bogner, J.R., Goebel, F.D., Nitschko, H., and von der Helm, K. (2000). Sequence analysis of the HIV-1 protease coding region of $18 \mathrm{HIV}-1$-infected patients prior to HAART and possible implications on HAART. J. Clin. Virol. 17, $137-141$.

Gehringer, H., von der Helm, K., Seelmeir, S., Weißbrich, B., Eberle, J., Nitschko, H. (2003). Development and evaluation of a phenotypic assay monitoring resistance formation to protease inhibitors in HIV-1-infected patients. J. Virol. Methods 109, 143-152.

Geoghegan, K.F., Spencer, R.W., Danley, D.E., Contillo Jr., L.G., and Andrews, G.C. (1990). Fluorescence-based continuous assay for the aspartyl protease of human immunodeficiency virus-1. FEBS Lett. 262, 119-122.

Gürtler, L.G., Hauser, P.H., Eberle, J., von Brunn, A., Knapp, S., Zekeng, L., Tsague, J.M., and Kaptue, L. (1994) A new subtype of human immunodeficiency virus type 1 (MVP-5180) from Cameroon. J. Virol. 68, 1581-1585.

Hanna, G.J., and Caliendo, A.M. (2001). Testing for HIV-1 drug resistance. Mol. Diag. 6, 253-263.

Harrigan, P.R., and Cote, H. (2000). Clinical utility of testing human immunodeficiency virus for drug resistance. Clin. Infect. Dis. 30 (Suppl. 2), 117-122.

Hertogs, K., de Bethune, M-P., Miller, V., Ivens, T., Schel, P., van Chauvenberge, A., van den Eynde, C., van Geren, V., Azijn, H., van Houtte, M. et al. (1998). A rapid method for simultaneous detection of phenotypic resistance to inhibitors of protease and reverse transcriptase in recombinant human immunodeficiency virus type 1 isolates from patients treated with antiretroviral drugs. Antimicrob. Agents Chemother. 42, 269276. 
Iga, M., Matsuda, Z., Okayama, A., Sugiura, W., Hashida, S., Morishita, K., Nagai, Y., and Tsubouchi, H. (2002). Rapid phenotypic assay for human immunodeficiency virus type 1 protease using in vitro translation. Virol. Methods 106, 25-37.

Klabe, R.M., Bacheler, L., Ala, P., Erickson-Viitanen, S., and Meek, J. (1998). Resistance to HIV protease inhibitors: a comparison of enzyme inhibition and antiviral potency. Biochemistry $37,8735-8742$.

Knight, C.G. (1995). Active-site titration of peptidases. Methods Enzymol. 248, 85-101.

Kraft, G.A., and Wang, G. (1994). Synthetic approaches to continuous assay of retroviral proteases. Methods Enzymol. 241, $70-68$.

Kusumi, K., Conway, B., Cunningham, S., Berson, C., Evans, A., Iversen, K., Colvin, D., Gallo, M.V., Coutre, S., and Shpaer, E.G. (1992). Human immunodeficiency virus type 1 envelope gene structure and diversity in vivo and after cocultivation in vitro. J. Virol. 66, 875-885.

Langmann, P., Zilly, M., Weißbrich, B., Desch, S., Väth, T., and Klinker, H. (2002). Therapeutic drug monitoring of indinavir in HIV-infected patients undergoing HAART. Infection 30, 1316.

Margren, P.-O., Lindgren, M.T., Gertow, K., Karlsson, R., Hämäläinen, M., and Danielson, H. (2001). Determination of interaction kinetic constants for HIV-1 protease inhibitors using optical biosensor technology. Anal. Biochem. 292, $207-218$

Maschera, B., Darby, G., Palu, G., Wright, L.L., Tisdale, M., Myers, R., Blair, E.D., and Furfine, E.S. (1996). Mutations in the viral protease that confer resistance to saquinavir increase the dissociation rate constant of the protease-saquinavir complex. J. Biol. Chem. 271, $33231-33235$.

Masquelier, B., Peytavin, G., Leport, C., Droz, C., Duran, S., Verdon, R., Besnier, J.-M., Chêne, G., Raffi, F., Brun-Vézinet, F., and the APROCO Study Group (2002). Mechanism of early virologic failure in antiretroviral-naïve patients starting protease inhibitor-containing regimens: the APROVIR study. J. Infect. Dis. $186,1503-1507$.

Matayoshi, E.D., Wang, G.T., Kraft, G.A., and Erickson, J. (1990). Novel fluorogenic substrates for assaying retroviral proteases by resonance energy transfer. Science 24, 954-958.

Miller V. (2001). International perspectives on antiretroviral re- sistance. Resistance to protease inhibitors. J. Acquir. Immune Defic. Syndr. 26 (Suppl. 1), 34-50.

Morrison, J.F. (1969). Kinetics of the reversible inhibition of enzyme catalysed reactions of tight-binding inhibitors. Biochim. Biophys. Acta 185, 269-285.

Morrison, J.F. (1982). The slow-binding and slow, tight-binding inhibition of enzyme-catalysed reactions. Trends Biochem. Sci. 7, 102-105.

Palmer, S., Shaker, R., and Merigan, T. (1999). Highly drug-resistant HIV-1 clinical isolates are cross-resistant to many antiretroviral compounds in current clinical development. AIDS $13,661-667$.

Petropoulos, C.J., Parkin, N., Limoli, K., Lie, Y., Wrin, T., Huang, W., Tian, H., Smith, D., Winslow, G.A., Capon, D.J., and Whitcomb, J.M. (2000). A novel phenotypic drug susceptibility assay for human immunodeficiency virus type 1. Antimicrob. Agents Chemother. 44, 920-928.

Richmann, D.D. (2001). HIV chemotherapy. Nature 410, 9951001.

Ristig, M., Arens, M., Kennedy, M., Powderly, W., and Tebas, P. (2002). Increasing prevalence of resistance mutations in antiretroviral-naive individuals with established HIV-1 infection from 1996-2001 in St. Louis. HIV Clin. Trials 3, 155-160.

Rodriguez-Rosado, R., Briones, C., and Soriano, V. (1999). Introduction of HIV drug-resistance testing in clinical practice. AIDS 13, 1007-1014.

Schmidt B., Korn K. and Walter H. (2002). Technologies for measuring HIV-1 drug resistance. HIV Clin. Trials 3, 227-236.

Vazquez-Rosales, G., García Lerma, G., Yamamoto, S., Switzer, W., Havlir, D., Folks, T., Richman, D.D., and Heneine W. (1999). Rapid screening of phenotypic resistance to nevirapine by direct analysis of HIV-1 reverse transcriptase activity in plasma. AIDS Res. Hum. Retroviruses 13, 1191-1200.

von der Helm, K., Seelmeir, S., Kisselev, A., and Nitschko, H. (1994). Identification, purification and cell culture assays of retroviral proteases. Methods Enzymol. 241, 89-104.

Wilson, S.I., Phylip, L.H, Mills, J.S., Gulnik, S.V., Erickson, J.W., Dunn B.M., and Kay J. (1997). Escape mutants of HIV-1 proteinase: enzymic efficiency and susceptibility to inhibition. Biochim. Biophys. Acta 1339, 113-125.

Received February 13, 2003; accepted April 14, 2003 